\title{
The System of School Mathematical Education in Ukraine
}

\author{
Z. Serdyuk ${ }^{1, *}$, A. Tkachenko ${ }^{2}$ \\ ${ }^{1}$ Department of Mathematics and Methods of Teaching Mathematics, Bohdan Khmelnytskyy National University at Cherkasy, Ukraine \\ ${ }^{2}$ Department of Physics, Bohdan Khmelnytskyy National University at Cherkasy, Ukraine \\ *Corresponding author: serdyuk_z@ukr.net
}

Received September 27, 2013; Revised October 10, 2013; Accepted November 26, 2013

\begin{abstract}
The article suggests an overview of secondary education characteristics in Ukraine; role, place and goals of studying mathematics in a Ukrainian secondary school; types of educational establishments are highlighted; terms of pupils' study on each of the three basic stages are commented on.. Place and goal of studying mathematics at secondary school is discussed in the article. The results of senior pupils' educational success monitoring on mathematics are analyzed and the examples of tests are given.
\end{abstract}

Keywords: full secondary education, studying mathematics, elementary school, secondary school, senior school

Cite This Article: Z. Serdyuk, and A. Tkachenko, "The System of School Mathematical Education in Ukraine.” American Journal of Educational Research 1, no. 11 (2013): 561-565. doi: 10.12691/education-1-11-18.

\section{Introduction}

Secondary education - a purposeful process of systematic knowledge mastering by students about nature, man, society, culture and production by means of cognitive and practical activity [4]. The result of this process is the intellectual, social and physical development of an individual. Secondary education is compulsory component of qualitative continuing education. One of the important components in the process of full-grown, socially active personality is the study of mathematics.

\section{General Characteristics of Secondary Education in Ukraine}

According to the Law of Ukraine about General Secondary Education [4] Ukrainians regardless of race, color, political, religious or other beliefs, sex, ethnic or social origin, property, residence, language or other characteristics are provided by accessibility and free of charge secondary education at state and municipal educational establishments.

Full general secondary education in Ukraine consists of three main stages: I level - elementary school that provides primary education; II level - elementary school that provides basic general education; III level - high school that provides full secondary education, usually with a core education.

According to the educational level provided by comprehensive educational establishments and the students' contingent, different types of secondary schools are distinguished. Schools of each of the three stages can function either together or independently.

To secondary schools (SS) belong [4]:

- the school of I-III level;

- specialized school (boarding school ) of the I-III level of in-depth study of certain subjects ;

- gymnasium - an educational establishment of the IIIII level with in-depth study of certain subjects according to the establishment profile;

- college - an educational establishment of the II-III level with philological and philosophical or cultural and aesthetic profile;

- lyceum - an educational establishment of the III level with specialized and pre-profile training (may provide educational services of the II level, for pupils starting from 7-8 form);

- boarding school of the I-III levels - an educational establishment with partial or complete state maintenance of children in need;

- special school of the I-III levels - an educational establishment for children who need physical and/or mental development correction;

- sanatorium school of the I-III levels - an educational establishment with the appropriate profile for children who need a long-term treatment;

- school of social rehabilitation - an educational establishment for children who need special upbringing conditions (separately for boys and girls);

- evening school of the II-III levels - an educational establishment for people who are unable to study at schools with full-time study;

- educational-rehabilitation center - an educational establishment for children with special educational needs because of complex developmental defects.

Term of education for getting full secondary education at secondary schools of the I-III levels is 11 years (Table 1 ). 
Table 1. Characteristics of the study terms at secondary educational establishments in Ukraine [4]

\begin{tabular}{|c|c|c|c|}
\hline SS & Term of study & Forms & Child's age \\
\hline I level & 4 years & $1-4$ & $6-10$ or $7-11$ years \\
\hline II level & 5 years & $5-9$ & $10-15$ or $11-16$ years \\
\hline III level & 2 years & $10-11$ & $15-17$ or $16-18$ years \\
\hline
\end{tabular}

\section{Mathematics as an Educational Subject in the System of Secondary Education in Ukraine}

Mathematics as an educational subject is studied at all levels of the full secondary education. According to the new State Standard of Secondary Education [2], the primary purpose of studying mathematics at school is to develop pupils' mathematical competence at the sufficient level for life in today's world, successful knowledge mastering of other educational subjects at school, providing students' intellectual development, their attention, memory, logic, culture, thinking and intuition development. Educational mathematics standards - is a normative document, which determines the minimum content of training, minimum requirements for mathematical content training, and content lines of school course on mathematics with educational levels [9]. State Standard has the following components: 1) a basic educational curriculum of the SS II-III levels; 2) the minimum of educational content; 3 ) the minimum of state requirements for levels of pupils' training. Thus, the State Standard - is the foundation, the basis for compiling of multi-level training programs and making corresponding textbooks on math. Textbooks should supply the Standard's demands and advanced level of studying mathematics.

According to the Cabinet of Ministers of Ukraine Regulation from 23.11.2011 № 1392, State Standard of Basic and Secondary Education (Second Generation) was approved, which is implemented at most of secondary schools since September 1, 2013, and in others schools should be provided since September 1, 2018 [2]. State Standard (Second Generation) for primary education was approved by the Cabinet of Ministers № 462 of 20.04.2011, and was in September 1, 2012 [3].

According to the State Standard [2], the main aims of mathematics study at secondary school are as follows:

- revealing the role and possibilities of mathematics in understanding and describing real processes and phenomena, providing realization of mathematics as the universal language of natural science and the organic component of general human culture;

- the development of students' logical, critical and creative thinking, the ability to express their opinions clearly and reasonably;

- providing of students' mathematical language mastering, mathematical symbols understanding, mathematical formulas and models as such that allow to describe the general properties of objects, processes and phenomena;

- formation the ability to substantiate logically and prove mathematical statements, to apply mathematical methods in the process of doing educational and practical sums, use mathematical knowledge and skills while other subjects study;

- formation the ability to estimate the correctness and rationality of mathematical sums solving, to prove the assertion, to recognize logically incorrect considerations, to make decisions under conditions of incomplete, redundant, accurate and probable information.

The study of mathematics at all levels is concentric: content sections in each form is being broadened and supplemented by relevant semantic lines.

\subsection{Features of Maths Learning at Elementary School}

At elementary school math is studied as a four-course with 4 hours weekly. The course of mathematics at elementary school is based on the following semantic lines: the numerals and operations with them; seizes; mathematical expressions; sums with a plot; space ratio, geometric figures. The basis of mathematics study at elementary school is arithmetic of integral numerals and seizes measuring. As propaedeutics by studying algebra and geometry some geometric shapes and their properties, numerical equalities, inequalities and so on are studied.

\subsection{Peculiarities of Studying Mathematics at General School.}

State Standard (second generation) determines the following tasks of educational sector which determine the content of mathematical education at basic school [2]:

1) broadening knowledge about the number (from natural numbers to real), a culture of oral, written, exact and approximate calculations formation;

2) functional system concepts formation, skills to use functions and their graphs to describe dependence between phenomena sizes and processes;

3) supplying students skills to perform transformations of algebraic expressions, solving equations, inequalities and their systems, to model using equations real situations, to explain the achieved results;

4) formation the notions about mathematical statistics and calculus of probability as separate sciences, about peculiarities of statistical research organization;

5) providing students' mastering of the geometry language, development of spatial idea, abilities to perform geometric constructions;

6) formation knowledge about geometrical shapes on a flat, their properties and abilities to apply the studied in the process of doing geometric sums;

7) review of the methods and techniques of mathematical proofs, formation of the skills to use them in the education process;

8) formation of knowledge about basic geometric sizes (length, area, volume, angle measure), how to find them among the flat and dimensional shapes, formation the abilities to apply their knowledge in educational and life situations.

Contents of mathematical education at basic school is determined by the following contentual lines: numbers, expressions, equations and inequalities, functions, elements of combinatory, theory of probability and statistics, geometric shapes, geometric seizes. Each is developed by taking into account the objectives of 
mathematical study at this level of schooling, which distinguishes two main stages: $5-6$ forms $(10-12$ years) and $7-9$ forms (12 - 16 years). Educational objectives on the first stage are implemented in the study of a single course on mathematics, on the second - two courses: algebra and geometry.

\subsection{Peculiarities of Studying Mathematics at Senior School.}

Senior school mainly functions as a profile, taking into account students and staff's needs and material facilities of the school. Priorities in teaching mathematics provide the students' understanding the nature of mathematical knowledge formation, to acquaint them with the ideas and methods of mathematics and its role in understanding and transforming reality, providing to a mastering system of mathematical knowledge and skills that are primarily educational, general cultural orientation and are necessary for successful study of other educational areas [5].

In 2003, by the decision of the Ministry of Education and Science of Ukraine the concept of specialized education in high school was approved [5]. According to this concept , the general tendency of seniour specialized school is its focus on broad differentiation, variety, multiprofile, integration of general and pre-professional education. Profility of study is implemented by the following main directions of specialization: social and humanities, natural and mathematical, technological, artistic and aesthetic, athletic. Social and humanitarian direction includes the following sections of study: philological, historical and legislative, economic, legislative, linguistic and others.

The State Standard of Secondary Education (second generation) [2] outlines the basic tasks educational area content at seniour school:
- extension of students' competences as to identical expressions transformation (degree, logarithmic, irrational, trigonometrical), doing the corresponding equations and inequalities;

- Completion of numerical function notion formation as a result of the study of degree, index, trigonometrical class functions, developing skills to use and to explore them, to apply for description and phenomena and processes study;

- Presentation of the ideas and techniques of differential and integral calculation, basic skills of their practical application forming;

-Practical competence forming as to recognition of accidental facts, the calculation of its probabilities, the use of basic statistical and probabilty models during learning and doing practical sums and working up experimental data in the process of natural sciences study;

- Knowledge system forming about spatial figures and their basic properties, methods of their surface areas and volumes computing, as well as skills to apply the knowledge while doing educational and practical sums;

- Forming an idea of mathematical theories axiomatic construction.

In high school the study of one of the main content lines - functional line. Students studying trigonometric, degree index, logarithmic functions, and their properties; operations of differentiation and integration. High school students continue studying these content lines: number and calculation, computation expressions and equations and inequalities transformation, geometric figures, elements of probability theory and mathematical statistics and so on.

The study of mathematics at senior school is offered to be organized in three levels: the level of standard, academic and specialized [5]. Distribution of hours on mathematics at all three levels of secondary education is presented in Table 2.

Table 2. Distribution of hours on mathematics on different levels of SS $[6,7,8]$

\begin{tabular}{|c|c|c|c|c|c|}
\hline School & Forms & $\begin{array}{c}\text { Number of hours wer week } \\
(1 \text { term/ } 2 \text { term) }\end{array}$ & $\begin{array}{c}\text { Total number of hours } \\
\text { per year }\end{array}$ & Subject & Levels \\
\hline Primary school & $1-4$ & 4 & 136 & Mathematics & Basic \\
\hline \multirow{5}{*}{$\begin{array}{l}\text { Secondary } \\
\text { school }\end{array}$} & $5-6$ & 4 & 140 & Mathematics & Basic \\
\hline & \multirow{2}{*}{$7-9$} & 2 & 70 & Algebra & \multirow{2}{*}{ Basic } \\
\hline & & 2 & 70 & Geometry & \\
\hline & \multirow{2}{*}{$8-9$} & 5 & 175 & Algebra & \multirow{2}{*}{$\begin{array}{l}\text { In-depth study of } \\
\text { mathematics }\end{array}$} \\
\hline & & 3 & 105 & Geometry & \\
\hline \multirow{10}{*}{ Seniour school } & \multirow{3}{*}{$10-11$} & 3 & 105 & Mathematics (consistent education) & Standard level \\
\hline & & $1 / 2$ & 54 & Algebra & \multirow{2}{*}{ Standard level } \\
\hline & & $2 / 1$ & 51 & Geometry & \\
\hline & 10 & 2 & 70 & \multirow{2}{*}{ Algebra } & \multirow{3}{*}{ Academic level } \\
\hline & 11 & 3 & 105 & & \\
\hline & \multirow{5}{*}{$10-11$} & 2 & 70 & Geometry & \\
\hline & & 5 & 175 & Algebra & \multirow{2}{*}{ Specialized level } \\
\hline & & 4 & 140 & Geometry & \\
\hline & & 5 & 175 & Algebra & \multirow{2}{*}{$\begin{array}{l}\text { In-depth study of } \\
\text { mathematics }\end{array}$} \\
\hline & & 4 & 140 & Geometry & \\
\hline
\end{tabular}


For example, at social and humanitarian classes students study math at standard level (3 hours per week), and only at economics classes of the same direction - at an academic level (Algebra - 2 hours per week, Geometry - 2 hours per week). Level of Standard - is a compulsory minimum of subject content that does not allow its further study (e.g. mathematics at classes of philological profile, etc.) [5].

In the current program on mathematics for secondary schools [7] state requirements for general education students at the standard level accordingly to the content of the educational material on algebra and geometry are regulated.

\section{Monitoring Senior School Pupils' Educational Success in Mathematics.}

To determine the students of humanities classes actual level of mathematical knowledge and skills monitoring of academic achievements should be held, which provides tracking of students' achievements, its prediction and improvement [1].

One of the most popular and effective methods for measuring students' achievements is testing. We have carried out testing to diagnose the 11th grade pupils' level in basic types of mathematical activity formation at a basic level of mathematics for $10^{\text {th }}$ form pupils; comparative analysis of the characteristics of the educational achievements of the 11th grade of secondary education classes and classes of social and humanitarian direction. Tests used in the experiment made in accordance with the Concept of specialized education in seniour school (level standard) [5] and plans on mathematics for specialized schools of humanities direction [8].

\subsection{Analysis of the Results of Monitoring.}

Testing of students' knowledge was conducted according to the following semantic lines: number and computation; equations and transformations; functions and their graphics; equations and inequalities; geometrical figures and their properties; geometrical sizes measuring. Diagnostics was based on all requirements [1]. Testing having conducted with pupils of 11 forms (total 457 pupils), who were divided into two groups: students of humanitarian classes (group G1 - 235 pupils) and students of secondary classes at Cherkasy and Cherkasy region and some specialized (non-humanitarian profile) forms (group G2 - 222 students). Students were asked to do 25 tasks on algebra and geometry for the 10th form. Test results are presented on Table 3 and Table 4.

Table 3. Division of pupils' success based on the successfully performed tasks

\begin{tabular}{|c|c|c|c|c|}
\hline $\begin{array}{c}\text { Number of } \\
\text { tasks }\end{array}$ & $\begin{array}{c}\text { Number of pupils G1, who performed tasks } \\
\text { successfully }\end{array}$ & $\begin{array}{c}\text { Success } \\
\text { percentage }\end{array}$ & $\begin{array}{c}\text { Number of pupils G2, who performed tasks } \\
\text { successfully }\end{array}$ & $\begin{array}{c}\text { Success } \\
\text { percentage }\end{array}$ \\
\hline $0-5$ & 6 & $2,55 \%$ & 5 & $2,25 \%$ \\
\hline $6-10$ & 67 & $28,51 \%$ & 61 & $27,48 \%$ \\
\hline $11-15$ & 109 & $46,38 \%$ & 107 & $48,2 \%$ \\
\hline $16-20$ & 53 & $22,56 \%$ & 42 & $18,92 \%$ \\
\hline $21-25$ & 0 & $0 \%$ & 7 & $3,15 \%$ \\
\hline Total & 235 & & 222 & \\
\hline
\end{tabular}

Table 4. Division of pupils' success based on the levels of pupils' educational achievements

\begin{tabular}{|c|c|c|c|c|c|c|}
\hline \multicolumn{7}{|c|}{ 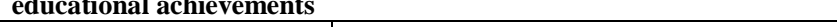 } \\
\hline & & & \multicolumn{4}{|c|}{$\begin{array}{l}\text { Levels of pupils' educational } \\
\text { achievements }\end{array}$} \\
\hline & & & high & $\begin{array}{l}\text { satis- } \\
\text { factory }\end{array}$ & middle & elementa-ry \\
\hline \multirow{4}{*}{$\begin{array}{l}\text { Number of } \\
\text { pupils, who } \\
\text { succeed a } \\
\text { certain level } \\
\text { of } \\
\text { educational } \\
\text { achievements } \\
\text { on the base } \\
\text { of testing } \\
\text { results }\end{array}$} & \multirow{2}{*}{$\mathrm{G}_{1}$} & 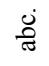 & 0 & 41 & 111 & 83 \\
\hline & & $\partial^{\circ}$ & 0 & 17,45 & 47,23 & 35,32 \\
\hline & \multirow{2}{*}{$\mathrm{G}_{2}$} & है & 5 & 44 & 111 & 62 \\
\hline & & $d^{\circ}$ & 2,25 & 19,82 & 50 & 27,93 \\
\hline
\end{tabular}

According to test results, offered in Table 2, it can be concluded that the majority of G2 students $(72,07 \%)$ have a high, medium, and a satisfactory knowledge level that suggests that they've mastered the basic level program on mathematics for the $10^{\text {th }}$ form . The group G1 64,68\% of pupils has satisfactory and middle level, indicating on a slightly lower quality of humanitarian students.

During our research, the following results of students' achievement in each of the offered content lines were received (Table 5).
Table 5. Division of pupils' success according to contentual units

\begin{tabular}{|c|c|c|}
\hline \multirow{2}{*}{ Content lines } & \multicolumn{2}{|c|}{ The number of correct answes (\%) } \\
\cline { 2 - 3 } & $\mathrm{G}_{1}$ & $\mathrm{G}_{2}$ \\
\hline Numbers and calculations & 56,36 & 58,7 \\
\hline Expressions and transformations & 42,05 & 50 \\
\hline Equations and inequalities & 44,89 & 48,37 \\
\hline Functions and their graphics & 51,14 & 45,11 \\
\hline Properties of geometrical figures & 45,08 & 52,9 \\
\hline Measuring of geometrical size & 55,68 & 53,26 \\
\hline
\end{tabular}

According to Table 5, we see that in both groups (about $56 \%$ of $\mathrm{G} 1$ and almost $59 \%$ of G2) students are able to perform various operations with numbers, compare them and calculate the results of expressions.

The following tasks of such a kind may be suggested:

Task 5 (variant 3). Calculate $\log _{5} 100+\log _{5} \frac{1}{4}$.

\begin{tabular}{|c|c|c|c|}
\hline $\mathbf{A}$ & B & C & D \\
\hline 2 & -2 & 1 & -1 \\
\hline
\end{tabular}

This is explained by the fact that students start studying numbers at primary school, taking into concideration that at certain level they start studying larger numeric sets (from natural to real or even complex numbers), and more 
complex operations with them. That is the decisive role is played by experience and skills worked for years.

On the second place (almost 56\% of G1 and G2 about $53 \%$ ) - the ability of students to measure geometric sizes, which is understandable, since these skills are related to calculating operations.

The following tasks of such a kind may be suggested:

Task 24 (variant 4). Oblique, the length of which equals a forms with a plane an angle of $60^{\circ}$. Orthogonal projection of this obligue onto the plane equals ...

\begin{tabular}{|c|c|c|c|}
\hline A & B & C & D \\
\hline$\frac{a}{2}$ & $\frac{a \sqrt{3}}{2}$ & $\frac{a \sqrt{3}}{3}$ & $\frac{a \sqrt{2}}{2}$ \\
\hline
\end{tabular}

Other findings in the groups being studied differ significantly. For example, mastering the technics of transformation and simplification of trigonometric, logarithmic and exponential expressions in group G2 is much better (50\%) than in group G1 (only 42,05 \%). This indicates a low development of logical thinking, memory and attention of students in humanities.

Mastered the ability to establish mutual arrangement of lines, line and plane, planes in space better than G2 $52,9 \%$ against $45,08 \%$ in the G1, indicating a lack of spatial thinking development and spatial imagination of students of humanities classes.

The following tasks of such a kind may be suggested:

Task 20 (variant 5). If the diagonals of a parallelogram are parallel to a plane $\alpha$, then the area of a parallelogram and the plane $\alpha \ldots$

\begin{tabular}{|c|c|c|c|}
\hline A & B & C & D \\
\hline have joint pots & converge & parallel & crosscut \\
\hline
\end{tabular}

On the contrary, the students of group G1 is better learned on "Functions and graphs" (51,14 \%), namely the properties of trigonometric graphs, degree, logarithmic functions than students of G2 (45,11\%).

The low level of mastering basic methods and ways of doing trigonometric, exponential and logarithmic equations and inequalities in both groups show the corresponding test results: 44,89\% (G1) and 48,37\% (G2).

The following tasks of such a kind may be suggested: Task 15 (variant 6). Undo the inequality:

$$
(0,2)^{-3 x-1}>\frac{1}{25}
$$

\begin{tabular}{|c|c|c|c|}
\hline $\mathbf{A}$ & B & C & D \\
\hline$(1 ;+\infty)$ & $(-\infty ; 1)$ & $(-\infty ;-1)$ & $(-1 ;+\infty)$ \\
\hline
\end{tabular}

In our opinion, the general level of mastered knowledge by students of both groups is low, because the success of each content unit tasks does not exceed $60 \%$. According to our observations both groups of students have opportunities to improve this level under conditions of improving methods of teaching mathematics.

\section{Conclusion}

Complete general secondary education in Ukraine consists of three basic levels: I level - primary school (4 years); II level - secondary school (5 years); III level senior profile school (2 years). According to educational level and pupils' peculiarities different types of educational establishments exist: secondary schools of IIII levels, gymnasiums, lyceums. Mathematics as educational subject is taught on each level of general secondary education, and in senior school pupils may choose educational profile and correspondent level of mathematical course studying - the standard level (profile for humanities), academic level (for economic, biological, chemical profile) or profile level (for physical and mathematical profile).

Analysis of mathematics education in secondary education of Ukraine proves that every Ukrainian child can get a general education and become fully developed, socially active person. Got knowledge, skills and ability in mathematics allow people of our country to become competitive while admission to higher educational institutions in Ukraine and abroad. Our further research will be directed on discovering common and different features in the education system of Ukraine and other Slavic countries.

\section{Acknowledgement}

We would like to thank the authors of the references who have helped us indirectly through their immortal books, journals while preparing this manuscript.

\section{Statement of Competing Interests}

The authors have no competing interests.

\section{References}

[1] Afanasjeva, O. M., Brodskyi, Y. S., Glyuza, O. O., Jevtuhova, O. V., Pavlov, O. L., Slipenko, A. K., Diagnostic set for helding monitoring for 4-11 form students in basic mathematical training, Navcalna knyga, Ternopil, 2005, 256.

[2] State standard of elementary and full secondary education. [Online]. Available:

http://mon.gov.ua/ua/activity/education/56/692/state_standards/.

[3] State standard of elementary education. [Online]. Available: http://mon.gov.ua/ua/activity/education/56/692/state_standards/.

[4] Law of Ukraine about general secondary education. [Online]. Available:

http://mon.gov.ua/ua/activity/education/56/692/normativnopravova-baza/.

[5] "Conception of profile education at senior school", Mathematics at school, № 1, 2-7, 2006.

[6] Burda, M. I., Malyovanyi, J. I., Nelin, J. P., Nomirovskyi, D. A., Pankov, A. V., Tarasenkova, N. A., Chemerys, M. V., Jakir, M. S., Mathematics. Educational plan for 5-9 form students of secondary educational establishments, K, 2012, 52: [Online]. Available: http://www.mon.gov.ua/ua//activity/ education/56/generalsecondary-education/educational_programs / 1349869088/.

[7] Mathematics. 5-12 forms. A plan for secondary education establishments, Perun, Kyiv, 2005, 64.

[8] Plans for secondary education establishments. Mathematics. Plans for profile education. Plans of special courses, clubs, Navchalna knyga, Kyiv, 2003, 302.

[9] Sljepkan, Z. I. Psychological and pedagogical, methodical basis of developmental training on mathematics, Pidruchyky i posibnyky, Ternopil, 2004, 240. 